Disubmit 03 Mei 2019

Diterima 30 Juni 2019

\title{
GAMBARAN POLA MENYUSUI IBU PADA NEONATUS: STUDI DESKRIPTIF
}

\section{OVERVIEW OF PATTERNS IN NEONATAL NURSING MOTHERS: DESCRIPTIVE STUDY}

\author{
Ni Komang Ayu Resiyanthi ${ }^{1}$, Heni Ekawati ${ }^{2}$, Anak Agung Ayu Sudiletari ${ }^{3}$, \\ Gusti Ayu Made Purnama Dewi ${ }^{4}$. \\ 1,2,3,4 STIKes Wira Medika Bali
}

\begin{abstract}
ABSTRAK
Pengetahuan merupakan dasar seorang ibu untuk melakukan perawatan dan menyusui eksklusif. Penelitian ini bertujuan untuk mengidentifikasi pola menyusui ibu pada neonatus. Penelitian ini merupakan penelitian deskriptif dengan pendekatan kuantitatif. Cara pengambilan sampel adalah purposive sampling pada130 ibu. Analisis data dengan analisis univariat. Hasil penelitian menunjukkan sebagian besar responden memiliki pengetahuan baik tentang pola menyusui ibu pada neonates sebanyak 66 orang $(50,77 \%)$. Sebaran pengetahuan pada responden sebagian besar menjawab benar pada pertanyaan tentang pengetahuan umum tentang proses menyusu sebanyak 49 orang $(37,69 \%)$, frekuensi menyusui ibu sebanyak 73 orang $(56,15 \%)$, frekuensi menyusui ibu sebanyak 73 orang $(56,15 \%)$, posisi ibu dan bayi saat proses menyusui sebanyak 50 orang $(38,46 \%)$, faktor yang mempengaruhi ASI ibu sebanyak 40 orang $(30,77 \%)$, faktor yang mempengaruhi pola menyusui ibu sebanyak masing 38 orang $(29,23 \%)$. Rekomendasi: Ibu lebih aktif untuk mencari informasi tentang pola menyusui yang baik dan juga asupan nutrisi yang baik sehingga prosuksi ASI lebih baik dan produksi asi lebih banyak. Sehingga dapat mencukupi kebutuhan bayi dalam pertumbuhan dan perkembangannya.
\end{abstract}

Kata Kunci: Pola menyusui, ibu, neonatus

\begin{abstract}
ABSTRACK
Knowledge is the basis of a mother for exclusive nursing and nursing. This study aims to identify maternal breastfeeding patterns in neonates. This research is a descriptive study with a quantitative approach. The sampling method was purposive sampling in 130 mothers. Data analysis with univariate analysis. The results showed that most respondents had good knowledge about breastfeeding patterns in neonates as many as 66 people $(50.77 \%)$. The distribution of knowledge to most respondents answered correctly on questions about general knowledge about the nursing process as many as 49 people (37.69\%), the frequency of breastfeeding as many as 73 people (56.15\%), the frequency of breastfeeding as many as 73 people (56.15\%), the position of the mother and baby during the breastfeeding process as many as 50 people (38.46\%), factors affecting breastfeeding for as many as 40 people (30.77\%), factors that influence the pattern of breastfeeding as
\end{abstract}


many as 38 people (29.23\%). Recommendation: Mothers are more active in finding information about good breastfeeding patterns and also good nutrition so that the milk production is better and the production of breast milk is more. So that it can meet the needs of infants in their growth and development.

Key words: Breastfeeding patterns, mothers, neonates

\begin{tabular}{ll}
\hline $\begin{array}{l}\text { Alamat Korespondensi } \\
\text { Email }\end{array}$ & $\begin{array}{l}\text { : STIKes Wira Medika Bali } \\
\text { :davyathaa@gmail.com }\end{array}$ \\
\hline
\end{tabular}

\section{PENDAHULUAN}

Kesehatan ibu dan anak telah menjadi isu penting baik skala nasional maupun internasional. Milenium Development Goals (MDGs), menyebutkan bahwa telah terjadi penurunan angka kematian anakdan peningkatan angka kesehatan ibu. Kematian bayi dibawah usia lima tahun dapat dikurangi jumlahnya dengan cara memberikan Air Susu Ibu (ASI). ASI merupakan nutrisi paling baik bagi bayi.

Bayi baru lahir (neonatus) adalah bayi yang berusia 0-28 hari (Kementerian kesehatan RI, 2010). World Health Organization (WHO) pada tahun 2012 kira-kira 3\% (3,6 juta) dari 120 juta bayi lahir mengalami asfiksia, hampir 1 juta bayi ini kemudian meninggal. Kehidupan pada masa neonatus merupakan masa paling rawan sebab terjadi penyesuaian fisiologis dari intrauterine ke lingkungan ekstrauterine. Salah satu penyesuaian yang terjadi adalah adanya perubahan berat badan pada neonatus.

Berat badan merupakan gambaran status nutrisi secara umum. Berat badan pada neonatus yang lahir aterm, $75 \%$ dari berat badannya tersusun oleh cairan tubuh. Ketidakcukupan nutrisi pada neonatus juga mempengaruhi adanya penurunan motilitas usus. Asupan ASI atau susu formula akan meningkatkan motilitas usus akibat peningkatan osmolaritas dalam usus meningkat. ASI memberikan perlindungan kepada bayi dari serangan mikroorganisme yang dapat menyebabkan infeksi. Selain itu manfaat ASI dapat menurunkan resiko penyakit diabetes, kanker tertentu, obesitas dan juga asma.

Upaya pencegahan yang dapat dilakukan agar masalah-masalah nutrisi pada neonatus berdasarkan Survey Demografi Kesehatan Indonesia (SDKI) 2006 menunjukkan bahwa hampir semua bayi $(95,9 \%)$ di Indonesia mendapat ASI, sebanyak 38,7 \% BBL mendapat ASI dalam 1 am setelah lahir dan 62,1\% bayi mendapat ASI dalam 1 hari setelah lahir. Pemberian ASI Ekslusif tidak diterapkan secara meluas. Hanya $64 \%$ anak umur dibawah 2 bulan yang mendapat ASI Eksklusif, persentase ini menurun menjadi $46 \%$ untuk anak $2-3$ bulan dan $14 \%$ untuk anak 4-5 bulan (SDKI 2006) .

Kementerian Kesehatan Republik Indonesia (2013) mengatakan bahwa salah satu indikator kesehatan yang dinilai keberhasilan pencapaiannya dalam Millennium Development Goals (MDGs) adalah status gizi balita. Air susu ibu yang diberikan secara eksklusif selama enam bulan merupakan nutrisi terbaik untuk bayi (American Academy of Pediatrics, 2005). Menurut Zareai, et al (2007), ASI mempunyai kandungan nutrisi baik dan seimbang yang sesuai dengan kebutuhan 
bayi, mempunyai kandungan seluruh nutrisi yang dibutuhkan bayi sampai dengan usia enam bulan yang dapat menunjang pertumbuhan fisik dan emosional dengan baik. American Academy of Pediatric menegaskan kembali rekomendasinya untuk menyusui ekslusif sampai bayi berumur 6 bulan dan baru bisa diberikan makanan pendamping ASI (MP-ASI) saat bayi berusia 6 bulan, dengan tetap memberikan ASI sampai minimal umur 2 tahun.

Menyusui menurut WHO adalah cara alami untuk memeberikan bayi nutrisi yang mereka butuhkan yang berguna untuk pertumbuhan dan perkembangannya di masa awal kehidupan. ASI eksklusif yang dianjurkan adalah dari bayi baru lahir sampai 6 bulan. Namun pada kenyataannya pemberian ASI pada bayi rata-rata di dunia hanya sebesar 38\%. Hal ini mempengaruhi angka kematian bayi di negara berkembang yang masih cukup tinggi yaitu sekitar 10 juta orang, yang $60 \%$ dari kematian tersebut seharusnya dapat dicegah dengan pemeberian ASI, yang sudah terbukti dapat meningkatkan angka kesehatan bayi hingga 1,3 juta bayi (Isnaini 2013 dalam Dindy 2016).

Penelitian terhadap 900 ibu di sekitar Jakarta, Bogor, Tangerang, Bekasi (1995) diperoleh fakta bahwa yang dapat memberi ASI eksklusif selama 4 bulan hanya sekitar 5\%, padahal 98\% ibu-ibu tersebut menyusui. Dari penelitian tersebut juga didapatkan bahwa 37,9\% dari ibu-ibu tersebut tidak pernah mendapatkan informasi khusus tentang ASI, sedangkan 70,4\% ibu tak pernah mendengar informasi tentang ASI eksklusif (Roesli, 2013).

Penelitian ini bertujuan untuk mengidentifikasi pola menyusui ibu pada neonatus.

\section{METODE PENELITIAN}

Penelitian ini dilakukan di wilayah kerja UPT Puskesmas Susut I, Kabupaten Bangli. Penelitian ini merupakan penelitian deskriptif korelasional dengan menggunakan pada ibu dengan Neonatus (0-28 hari) sebagai populasi. Penentuan sampel dengan menggunakan metode purposive sampling pada ibu yang memiliki pada ibu dengan Neonatus ( $0-28$ hari). Variabel bebas dalam penelitian ini adalah Pola menyusui ibu pada neonatus. Pengumpulan data diawali dengan penyebaran kuesioner yang mengukur pola ibu dalam pemberian ASI.

Adapun data yang dianalisis secara univariat meliputi pengetahuan ibu, pengetahuan umum tentang proses menyusu, frekuensi menyusui ibu, posisi dalam menyusui, faktor-faktor yang mempengaruhi produksi ASI dan faktor-faktor yang mempengaruhi produksi ASI.

\section{HASIL DAN DISKUSI}

\section{HASIL}

1. Hasil Analisis Univariat

a. Tingkat Pengetahuan

Hasil analisis tingkat pengetahuan ibu adalah sebagai berikut: 
Tabel 1. Distribusi Responden berdasarkan Tingkat Pengetahuan Ibu di Pengetahuan Ibu di Wilayah Kerja UPT Puskesmas Susut I Bangli

\begin{tabular}{lcc}
\hline Varibel & n & $(\mathbf{\% )}$ \\
\hline Baik & 64 & 49,23 \\
\hline $\begin{array}{l}\text { Perlu } \\
\text { Ditingkat } \\
\text { kan }\end{array}$ & 66 & 50,77 \\
\hline Jumlah & 130 & 100 \\
\hline
\end{tabular}

Berdasarkan tabel 1, menunjukkan bahwa sebagian besar responden memiliki pengetahuan dalam kategori perlu ditingkatkan sebanyak 66 orang $(50,77 \%)$.

b. Pengetahuan umum tentang proses menyusu

Hasil analisis Pengetahuan umum tentang proses menyusu adalah sebagai berikut:

Tabel 2. Distribusi Responden berdasarkan Pengetahuan Umum tentang Proses Menyusudi Wilayah Kerja UPT Puskesmas Susut I Bangli

\begin{tabular}{ccc}
\hline Varibel & n & $\mathbf{( \% )}$ \\
\hline Benar 4 & 49 & 37,69 \\
\hline Benar 3 & 73 & 56,15 \\
\hline Benar 2 & 7 & 5,38 \\
& & \\
\hline Benar 1 & 1 & 0,78 \\
& & 100 \\
\hline Jumlah & 130 & \\
\hline
\end{tabular}

Berdasarkan tabel 2, menunjukkan sebagian besar responden dapat menjawab benar semua pertanyaan tentang pengetahuan umum tentang proses menyusu sebanyak 49 orang $(37,69 \%)$.

c. Frekuensi Menyusui Ibu

Hasil analisis frekuensi menyusui adalah sebagai berikut:

Tabel 3. Distribusi Responden berdasarkan Frekuensi Menyusui Ibu di Wilayah Kerja UPT Puskesmas Susut I Bangli

\begin{tabular}{ccc}
\hline \multicolumn{1}{c}{ Varibel } & $\mathbf{n}$ & $\mathbf{( \% )}$ \\
\hline Benar 4 & 73 & 56,15 \\
\hline Benar 3 & 47 & 6,15 \\
\hline Benar 2 & 10 & 7,7 \\
\hline Benar 1 & 0 & 0 \\
\hline Jumlah & 130 & 100 \\
\hline
\end{tabular}

Berdasarkan tabel 3, menunjukkan sebagian besar responden dapat menjawab benar semua pertanyaan tentang frekuensi menyusui ibu sebanyak 73 orang $(56,15 \%)$. 
d. Posisi ibu dan bayi saat menyusui

Hasil analisis posisi ibu dan bayi saat menyusui adalah sebagai berikut:

\begin{tabular}{lcc}
\hline \multicolumn{1}{c}{ Varibel } & n & $\mathbf{( \% )}$ \\
\hline Benar 6 & 50 & 38,46 \\
\hline Benar 5 & 50 & 38,46 \\
\hline Benar 4 & 22 & 16,92 \\
\hline Benar 3 & 6 & 4,62 \\
\hline Benar 2 & 2 & 1,54 \\
\hline \multicolumn{1}{c}{ Jumlah } & 180 & 100 \\
\hline
\end{tabular}

Berdasarkan tabel 4, menunjukkan sebagian besar responden menjawab benar pada enam (semua) dan lima pertanyaan tentang posisi ibu dan bayi saat proses menyusui sebanyak masing - masing 50 orang $(38,46 \%)$.

e. Faktor-Faktor yang mempengaruhi produksi ASI

Hasil analisis faktor-faktor yang mempengaruhi produksi ASI adalah sebagai berikut:

\begin{tabular}{lcc}
\hline \multicolumn{1}{c}{ Varibel } & $\mathbf{n}$ & $\mathbf{( \% )}$ \\
\hline Benar 7 & 16 & 12,31 \\
\hline Benar 6 & 35 & 26,92 \\
\hline Benar 5 & 40 & 30,77 \\
\hline Benar 4 & 37 & 28,46 \\
\hline Benar 3 & 2 & 1,54 \\
\hline Jumlah & 130 & 100 \\
\hline
\end{tabular}

Berdasarkan tabel 5, menunjukkan sebagian besar responden menjawab benar pada lima pertanyaan tentang faktor - faktor yang mempengaruhi ASI ibu sebanyak 40 orang $(30,77 \%)$.

f. Faktor-faktor yang mempengaruhi pola menyusui Ibu

Hasil analisis faktor-faktor yang mempengaruhi pola menyusui ibu adalah sebagai berikut:

\begin{tabular}{lcc}
\hline \multicolumn{1}{c}{ Varibel } & n & $\mathbf{( \% )}$ \\
\hline Benar 9 & 28 & 21,54 \\
\hline Benar 8 & 38 & 29,23 \\
\hline Benar 7 & 21 & 16,15 \\
\hline Benar 6 & 38 & 29,23 \\
\hline Benar 5 & 4 & 3,08 \\
\hline Benar 4 & 1 & 0,77 \\
\hline Jumlah & 130 & 100 \\
\hline
\end{tabular}

Berdasarkan tabel 6, menunjukkan sebagian besar responden menjawab benar pada delapan dan enam pertanyaan tentang faktor - faktor yang mempengaruhi pola menyusui ibu sebanyak masing - masing 38 orang $(29,23 \%)$.

\section{PEMBAHASAN}

1. Tingkat Pengetahuan

Hasil penelitian menunjukkan bahwa sebagian besar responden perlu meningkatkan pengetahuan mengenai hal - hal yang berkaitan dengan ASI eksklusif. Pengetahuan yang dimaksud pada penelitian ini meliputi: pengetahuan 
umum tentang proses menyusu, frekuensi menyusui ibu, posisi ibu dan bayi saat proses menyusui, faktoryang mempengaruhi produksi ASI, faktoryang mempengaruhi pola menyusui ibu.

Beberapa hasil penelitian yang sejalan dengan penelitian ini di antaranya: Penelitian Handayani, Yunengsih dan Solikhah (2014) yang melakukan penelitian tentang hubungan pengetahuan dan tekhnik menyusui dengan pemberian ASI Eksklusif di Wilayah Kerja Puskesmas Pengasih II Kabupaten Ponorogo. Responden penelitian adalah ibu yang mempunyai bayi berusia enam sampai 12 bulan sebanyak 142 orang. Hasil penelitian menunjukkan bahwa sebagian besar responden mempunyai pengetahuan rendah tentang tekhnik menyusui $(57 \%)$.

Penelitian yang dilakukan Nukpezah, Ninnoni, dan Nuvor (2018). Peneliti melakukan studi tentang Pengetahuan dan praktik menyusui eksklusif padaa ibu di kota metropolis tamale di Ghana. Peneliti mengambil data pada 393 pasangan ibu-bayi. Hasil penelitian menunjukkan bahwa mayoritas responden telah mendengar tentang menyusui eksklusifsebanyak 277 responden $(70,5 \%)$ tetapi memiliki pengetahuan yang tidak memadai tentang ASI eksklusif.

Adapun beberapa hasil penelitian yang bertentangan dengan penelitian ini di antaranya: Penelitian Alfaleh (2013) tentang persepsi dan pengetahuan menyusui pada beberapa wanita di Saudi Arabia. Penelitian dilakukan pada 332 partisipan. Hasil penelitian menunjukkan bahwa sebagian besar partisipan percaya bahwa cara terbaik untuk memberi makan pada bayi baru lahir sebanyak $86 \%$. Walaupun begitu, rerata menyusui di Saudi Arabia masih pada tingkat rendah yang mengkhawatirkan dibandingkan dengan standar internasional. Hal ini disebabkan kontribusi beberapa hal seperti: kurangnya kelas antenatal yang terstruktur dengan baik, dukungan ibu pada periode segera setelah melahirkan, dan kurangnya dukungan masyarakat untuk menyusui.

Studi antropologi dari Ahmed, Chaudhry, Riaz, Batool dan Farooq (2014) tentang pengetahuan dan praktik menyusui pada 138 ibu menyusui. Hasil penelitian menunjukkan bahwa sebagian besar menyatakan bahwa menyusui sehat untuk bayi sebanyak $93,4 \%$ responden. Pada penelitian ini ditemukan bahwa praktik menyusui sedikit mirip dengan hasil studi pola penyusui di Asia.

Pengetahuan (kognitif) merupakan hasil penginderaan terhadap suatu objek tertentu melalui pancaindera manusia yakni indera penglihatan, pendengaran, penciuman, rasa dan raba (Notoatmodjo, 2012). Tingkatan dari pengetahuan selain mengingat kembali, seseorang bisa menjelaskan kembali suatu informasi juga termasuk di dalamnya dapat menggunakan materi yang telah diketahui pada situasi nyata sehingga tahap awal untuk mengidentifikasi aplikasi menyusui terlebih dahulu mengidentifikasi pengetahuan ibu tentang menyusui sebagai dasar suatu perilaku.

Teori tersebut diatas berbanding terbalik dengan penelitian yang dilakukan olehVijayalaksmi, Susheela dan Mythili (2015) mengenai pengetahuan, sikap dan praktik menyusui pada ibu post partum. Penelitian dilakukan pada $122 \mathrm{ibu}$ post partum. Hasil penelitian menunjukkan bahwa mayoritas responden menyusui bayi $(88,5 \%)$, pengetahuan mayoritas responden berada dalam kategori sangat baik $(M \pm S D: 12.05 \pm 1,74)$. Selain didapatkan hasil penelitian bahwa pengetahuan responden dalam kategori sangat baik tetapi berbanding terbalik dengan perilaku menyusui ASI eksklusif yang berada dalam kategori 
rendah. Penelitian ini diperkuat dengan penelitian Nukpezah, Ninnoni, dan Nuvor (2018). Salah satu hasil penelitian didapatkan bahwa praktik menyusui eksklusif di komunitas tempat penelitian termasuk kategori rendah. Penelitian mengenai hambatan menyusui eksklusif dilakukan oleh Thet, Khaing, Smith, Sudhinaraset, Oo dan Aung (2016). Penelitian kualitatif dilakukan pada 24 orang ibu yang mempunyai bayi usia $6-24$ bulan, ayah 10 orang dan ibu atau ibu mertua (nenek) sebanyak 10 orang. Hasil penelitian didapatkan bahwa hambatan utama menyusui eksklusif adalah kepercayaan ibu, ayah dan nenek bahwa menyusui eksklusif tidak cukup untuk bayi dan makanan padat serta air yang dibutuhkan oleh bayi. Hambatan menyusui eksklusif dihadapi oleh ibu dikarenakan kebutuhan untuk kembali bekerja diluar rumah dan masalah kesehatan.

\section{SIMPULAN}

\section{SIMPULAN DAN SARAN}

1. Sebagian besar responden memiliki pengetahuan dalam kategori yang perlu ditingkatkan sebanyak 66 orang $(50,77 \%)$

2. Sebagian besar responden sebagian besar responden dapat menjawab benar semua pertanyaan tentang pengetahuan umum tentang proses menyusu sebanyak 49 orang $(37,69 \%)$.

3. Sebagian besar responden dapat menjawab benar semua pertanyaan tentang frekuensi menyusui ibu sebanyak 73 orang $(56,15 \%)$.

4. Sebagian besar responden menjawab benar pada enam (semua) dan lima pertanyaan tentang posisi ibu dan bayi saat proses menyusui sebanyak masing masing 50 orang $(38,46 \%)$.

5. Sebagian besar responden menjawab benar pada lima pertanyaan tentang faktor - faktor yang mempengaruhi ASI ibu sebanyak 40 orang $(30,77 \%)$.

6. Sebagian besar responden menjawab benar pada delapan dan enam pertanyaan tentang faktor - faktor yang mempengaruhi pola menyusui ibu sebanyak masing - masing 38 orang $(29,23 \%)$.

\section{SARAN}

1. Responden

Diharapkan agar para Ibu lebih aktif untuk mencari informasi tentang pola menyusui yang baik dan juga asupan nutrisi yang baik sehingga prosuksi ASI lebih baik dan produksi asi lebih banyak. Sehingga dapat mencukupi kebutuhan bayi dalam pertumbuhan dan perkembangannya.

2. Institusi Pendidikan

Diharapkan agar institusi pendidikan dapat menyediakan kajian pustaka yang mendukung dalam proses pembelajaran yang berkaitan dengan ASI, pola menyusui dan nutrisi yang baik untuk pertumbuhan dan perkembangan bayi.

3. Peneliti Selanjutnya Peneliti menyarankan untuk meneliti faktor lain seperti dukungan dan juga budaya setempat yang dapat mempengaruhi pola ibu dalam menyusui ibu. 


\section{DAFTAR PUSTAKA}

Ahmed, A., Chaudhry, A.G., Riaz, A., Batool, A., dan Farooq, H. (2014). Breastfeeding Knowledge and Practices: An Anthropological Study of Lactating Mothers on Noor Pur Shahan Islamabad. Available at:

www.academia.edu/download/34776325/Breastfeeding_knowledge_and_pratices - final.pdf

Alfaleh, K.M. (2013). Perception and Knowledge of Breastfeeding Among Females in Saudi Arabia. Journal of Taibah Medical Sciences 9(2). Available at: https://www.sciencedirect.com/science/article/pii/S1658361213001030/pd fft?md5=14033c903a26f3ef45598d884a1d5878\&pid=1-s2.0S1658361213001030-main.pdf

Astutik, R. Y. (2014). Payudara dan Laktasi. Jakarta: Salemba Medika.

Handayani, L., Yunengsih., dan Solikhah. (2014). Hubungan Pengetahuan dan Tekhnik Menyusui dengan Pemberian ASI di Wilayah Kerja Puskesmas Pengasih II Kabupaten Kulonprogo. Journal Kesehatan Masyarakat Indonesia Volume 6 (3). Available at: http://jos.unsoed.ac.id/index.php/kesmasindo/article/view/79

Mardalena, I. (2017). Dasar-dasar Ilmu Gizi dalam Keperawatan. Yogyakarta: Pustaka Baru Press.

Notoatmodjo, S. (2012). Promosi kesehatan dan perilaku kesehatan. Jakarta: Rineka Cipta

Nukpezah, R.M., Ninnoni, J.P.K dan Nuvor, S.V. (2018). Knowledge and practice of exclusive breastfeeding among mothers in the tamale metropolis of Ghana. Journal of Republic Health 15 (1). Available at:https://www.researchgate.net/publication/327169849_Knowledge_and_ practice_of_exclusive_breastfeeding_among_mothers_in_the_tamale_metr opolis_of_Ghana

Septiari, B. B. (2012). Mencetak Balita Cerdas dan Pola Asuh Orang Tua. Yogyakarta: Nuha Medika.

Thet, M.M., Khaing, E.E., Smith, N.D., Sudhinaraset, M., Oo, S., dan Aung,T. (2016). Barriers to exclusive breastfeeding in the Ayeyarwaddy Region in Myanmar: Qualitative finding from mothers, grandmothers, and husbands. Journal of appetite 96 (2016).Available at: https://www.sciencedirect.com/science/article/pii/S0195666315300118

Vijayalaksmi, P., Susheela., \& Mythili, D. (2015). Knowledge, attitudes, and breast feeding practices of postnatal mothers: A cross sectional survey. International Journal of Health Sciences, 9:4.Available at:https://www.ncbi.nlm.nih.gov/pmc/articles/PMC4682591/ 